\title{
In memoriam: Professor Alois F. Schärli
}

\author{
Prem Puri ${ }^{1,2}$
}

Published online: 21 May 2018

c) Springer-Verlag GmbH Germany, part of Springer Nature 2018

A great sense of sadness marked the recent death of Professor Alois F. Schärli, who passed away on February 25, 2018 after a long illness. Alois was a highly respected member of the global pediatric surgical community, an outstanding surgeon and teacher, innovative researcher and a great advocate for the welfare of children (Fig. 1).

Alois was born on April 25, 1934 in Zell, a small village situated in the middle of a triangle cornered by Bern, Basle and Lucerne. He studied medicine in Freiborg and Bern and graduated in 1960. In 1961, he started general surgery training at the Inselspital Bern under Professor Lenggenhager. Upon the completion of general surgery training, Alois started pediatric surgical training in 1964 in Bern under Professor Marcel Bettex. During his pediatric surgical training he spent 2 years (1967-1969) in the United States, a year in Pittsburgh with Dr. W.B. Kiesewetter and a year in Boston working with Dr. F.D. Moore. He returned from the United States in 1969 and started as a staff member in the Department of Pediatric Surgery in Bern. In 1971, at the young age of 37, he was appointed as the Director of Pediatric Surgery at the newly built Children's Hospital in Lucerne. He was the head of this Department for the next 28 years and was responsible for developing a centre of excellence for pediatric surgery, attracting visitors from all over the world.

Alois had many research interests in very diverse areas of pediatric surgery. His primary focus of investigative work was on enteric plexus disorders in children. He had close collaboration with the Basle pathologist, Professor Meier-Ruge which resulted in various research projects and publications. He was very productive and published over 240 scientific articles in peer-reviewed journals, numerous

Prem Puri

prem.puri@ncrc.ie

1 National Children's Research Centre, Our Lady's Children's Hospital, Dublin, Ireland

2 School of Medicine and Medical Science, Conway Institute of Biomolecular and Biomedical Research, University College Dublin, Dublin, Ireland
Fig. 1 Professor Alois F. Schärli (1934-2018)

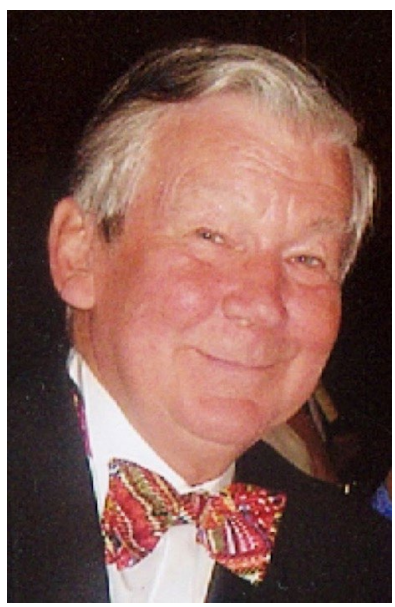

chapters and six textbooks including an authoritative text book for nurses.

His extraordinary ability as a leader in our speciality was recognized by many awards and honours. Many pediatric surgical organizations around the world bestowed Honorary Membership on Alois. To name a few, he was an Honorary member of the American Academy of Pediatrics (surgical section), American Pediatric Surgical Association, Canadian Association of Pediatric Surgeons, Japanese Society of Pediatric Surgeons, Royal Australasian College of Surgeons. He was the first recipient of the prestigious Rehbein Medal, the highest honour bestowed on a pediatric surgeon by the European Paediatric Surgeons' Association.

Alois was a dynamic and visionary leader in our speciality. One of his most important contributions to the development of pediatric surgery was the creation of the Journal "Pediatric Surgery International". He realized that there was only one Journal in our speciality in the English language and that there was a need for another journal. He met with Professor Michael Höllwarth and Professor Siegfried Hofmann von Kap-herr in Obergurgl, Austria in 1984 to discuss further his proposal. They all agreed that the time was right to have a new journal and this would benefit pediatric 

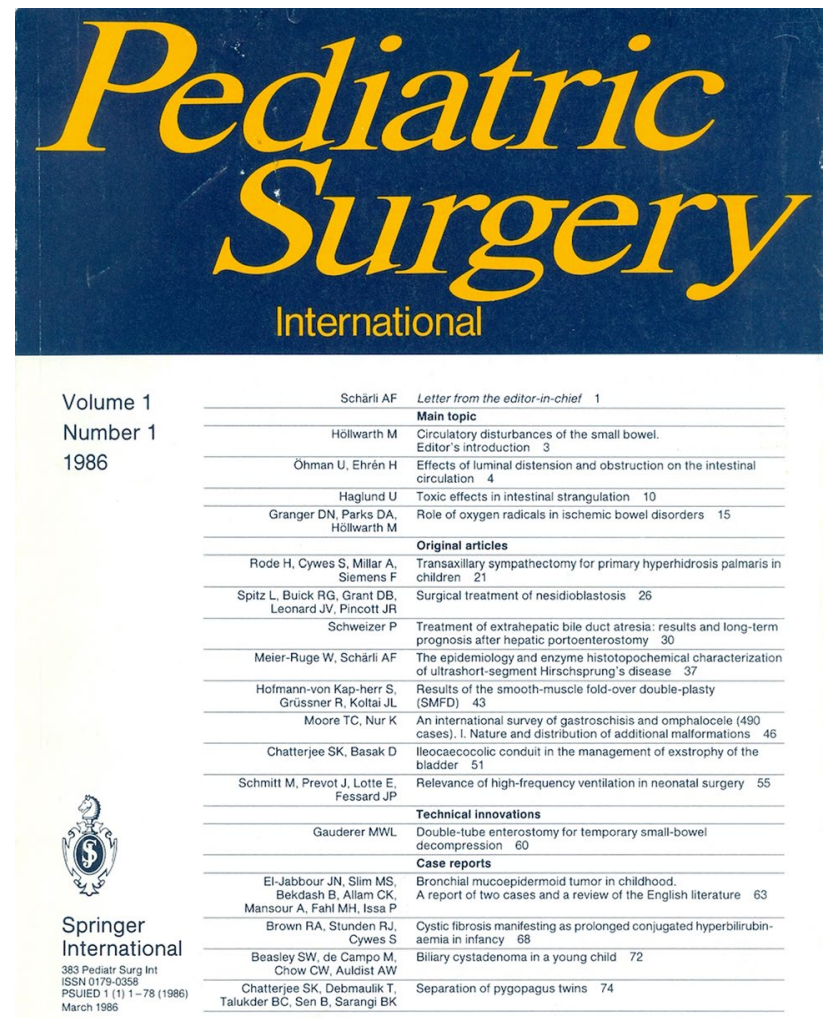

Fig. 2 First issue of Pediatric Surgery International published in March 1986

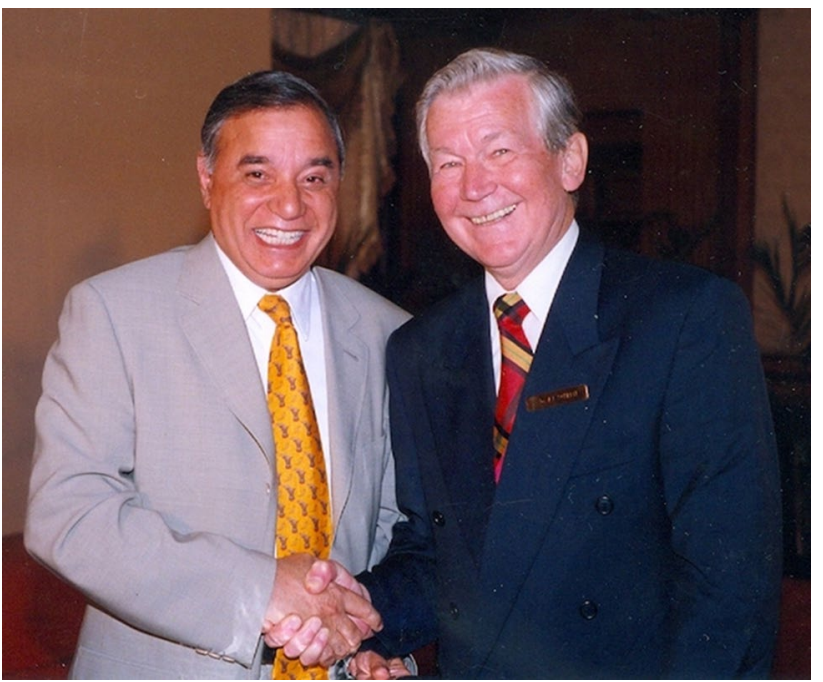

Fig. 3 Professor Alois F. Schärli and Professor Prem Puri in Lucerne in 2001
Fig. 4 Bronze sculpture of Ambroise Paré, a famous sixteenth century French surgeon, who first described diaphragmatic hernia in 1575 (Courtesy of Professor Michael Höllwarth)

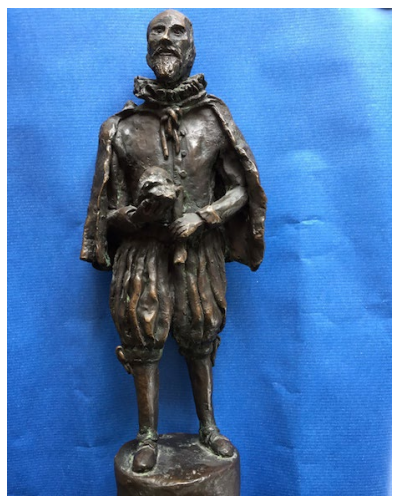

surgeons worldwide both in the developed and the developing world. Alois was the founding Editor-in-Chief of Pediatric Surgery International. The first issue was published in March 1986 and in the Editorial Alois wrote "The goal of the Pediatric Surgery International is to complement the existing literature, not to promote competition" (Fig. 2). He retired in 2001 and handed over the role of Editor-in-Chief to me. For me personally, it was a privilege to have known and worked with such an extraordinary person (Fig. 3).

His other great passions were Arts and Astronomy. Over the years he handcrafted many beautiful works of art, from drawings to bronze sculptures. He finely executed several sculptures in bronze and also applied his skills to the famous surgeons of the past (Fig. 4).

Alois is survived by his wife Leni, daughter Katrin, sonin-law Tobias and grand-daughters, Lena and Julie Marie. Leni, had always been by his side and played an important role in strengthening the bond of friendship among his international colleagues.

Alois was an inspirational and unique person. He meant so much to so many pediatric surgeons not only for the remarkable contributions he made to our speciality but for his love of meeting pediatric surgeons from all over the world, talking to them and listening to their views. He was a remarkable person who will always be remembered with fondness and gratitude by all who knew him personally.

Prem Puri 